\title{
Ressignificação da violência: \\ O grupo reflexivo "As Marias" sob as perspectivas das epistemologias do sul
}

GALVÃO, lanne'

\section{RESUMO}

A sociedade é marcada por processos que relativizam as violências sofridas pelas mulheres, havendo resistência ao fortalecimento das relações pautadas a partir da igualdade de gênero. O advento da Lei 11.340/06 (Maria da Penha) traz ao ordenamento jurídico uma nova perspectiva de políticas públicas voltadas às mulheres. Como consequência dessa lei, Caruaru conta com O Centro de Referência da Mulher Maria Bonita, que oferece atendimento psicológico, social e jurídico, assim como o Grupo Reflexivo: As Marias. Pode-se perceber através da vivência no grupo, noções de reconhecimento na dor do outro e perspectivas de fortaleza. A pesquisa é realizada através da observação do empoderamento das mulheres com o grupo reflexivo. Com isso, percebe-se que a construção do conhecimento se dá de forma significativa através do outro, de cada história de vida e do contato com o humanizante, possibilitando novas formas de ressignificar a violência através do conhecimento e reconhecimento.

Violência doméstica e familiar. Ressignificação. Epistemologias do Sul.

\section{Reframing of violence: The reflective group "As Marias" from the perspective of southern epistemologies}

\section{ABSTRACT}

The society is marked by processes that relativize the violence suffered by women, there is resisting of the strengthening of relations based on gender equality. The advent of Law 11.340/06 (Maria da Penha) brings to the legal system a new perspective of public policies aimed at women. As a consequence of this law, Caruaru has The Maria Bonita Women's Reference Center, which offer psychological, social and legal assistance, as well as the Reflective Group: As Marias. It can perceive through the experience in the group, notions of recognition in the other's pain and their perspectives of fortitude. The research is conducted by observing women's empowerment with the reflective group. Thus, it's clear that the construction of knowledge takes place significantly through the other, with their life story and the contact with the humanizing, enabling new ways of resignifying violence through knowledge and recognition.

\footnotetext{
${ }^{1}$ Professora do Instituto Adelmar Bezerra Assessoria Jurídica da Secretaria de Políticas para Mulheres de Caruaru. E-mail: iannegalvaoadv@hotmail.com. Lattes: http://lattes.cnpq.br/7477485656968725. ORCID: https://orcid.org/0000-0001-7865-8724.
}

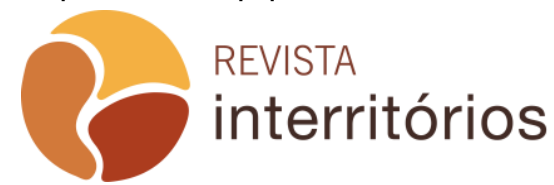

Interritórios | Revista de Educação Universidade Federal de Pernambuco, Caruaru, BRASIL | V.6 N.10 [2020] 
Domestic and family violence. Reframing. Southern epistemologies.

\section{Reasignación de la violencia: el grupo reflexivo "As Marias" desde la perspectiva de las epistemologías del sur}

\section{RESUMEN}

La sociedad es marcada por procesos que hacen que la violencia que sufren las mujeres sea relativa, teniendo resistencia al fortalecimiento de las relaciones basadas en la igualdad de género. El advenimiento de la Ley 11.340/06 (Maria da Penha) trae al sistema legal una nueva perspectiva de las políticas públicas dirigidas a las mujeres. Como resultado de esta ley, Caruaru cuenta con el Centro de Referencia para Mujeres Maria Bonita, que ofrece asistencia psicológica, social y legal, así como el Grupo Reflexivo: As Marias. Es posible percibir a través de la experiencia en el grupo, nociones de reconocimiento en el dolor del otro y perspectivas de fortaleza. La investigación se lleva a cabo a través de la observación del empoderamiento de las mujeres con el grupo reflexivo. Por lo tanto, está claro que la construcción del conocimiento se lleva a cabo de manera significativa a través del otro, a través de cada historia de vida y contacto con el humanizador, permitiendo nuevas formas de replantear la violencia a través del conocimiento y el reconocimiento.

Violencia doméstica y familiar. Resignificación Epistemologías del sur.

\section{Ridefinizione della violenza: il gruppo riflessivo "As Marias" dal punto di vista delle epistemologie del sud}

\section{SINTESE}

La società è caratterizzata da processi che relativizzano la violenza subita dalle donne, con resistenza al rafforzamento delle relazioni basate sulla parità di genere. L'avvento della legge 11.340 / 06 (Maria da Penha) porta al sistema giuridico una nuova prospettiva di politiche pubbliche rivolte alle donne. Come risultato di questa legge, Caruaru ha il Centro di riferimento per le donne Maria Bonita, che offre assistenza psicologica, sociale e legale, nonché il Gruppo Riflettente: As Marias. È possibile percepire attraverso l'esperienza nel gruppo, le nozioni di riconoscimento nel dolore dell'altro e le prospettive di forza. La ricerca viene condotta attraverso l'osservazione dell'empowerment delle donne con il gruppo riflessivo. In questo modo, è chiaro che la costruzione della conoscenza è condotta in modo significativo l'una con l'altra, attraverso ogni storia di vita e contatto con l'umanizzatore, consentendo nuovi modi di ripensare la violenza attraverso la conoscenza e il riconoscimento.

Violenza domestica e familiare. Risignificazione. Epistemologie del sud.

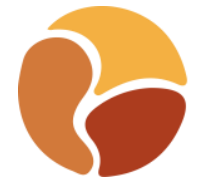




\section{INTRODUÇÃO}

A violência contra a mulher pode ser compreendida como uso intencional de poder ou força física, que possa resultar em lesão, dano psicológico ou físico, e até morte. Consonante com essa definição, Saffioti (2015) aduz que a violência do macho contra a mulher, expressa de diferentes formas - ironia, espancamento, reprodução forçada, estupro, homicídio etc. - é constitutiva da organização social de gênero no Brasil.

Percebe-se que quando há o debate sobre violência de gênero ela é sempre associada ao poder, que é a aniquilação de um ator social por outro, onde a mulher, inferior nessa relação, é objetificada pelo agressor. A violência de gênero é potencializada na medida em que o homem é incentivado pela sociedade a exacerbar os conceitos atribuídos ao gênero masculino, sendo o homem sinônimo de agressividade. De outro modo, a mulher é estimulada a suportar a violência, muitas vezes como forma de proteger sua própria sobrevivência e sua moral na sociedade. Para Gebara (2017, p.18), a mulher foi subalternizada pela função natural da procriação e do cuidado, isso levou especialmente aos filósofos, a fortalecer o silenciamento das mulheres em relação a outros atos.

Como já mencionado, as violências incluem diversos tipos de manifestações: violência física, psicológica, moral, patrimonial, sexual, intrafamiliar, doméstica e institucional. No Brasil, o primeiro marco legislativo de proteção a violência é a Lei 11.340/06 (Maria da Penha). O instrumento legislativo traz em seu conteúdo, mais precisamente no artigo $3^{\circ}$, $\S 1^{\circ}$ que, "o poder público desenvolverá políticas que visem garantir os direitos humanos das mulheres no âmbito das relações domésticas e familiares no sentido de resguardá-las de toda forma de negligência, discriminação, exploração, violência, crueldade e opressão".

A lei supramencionada aborda políticas públicas de prevenção e enfrentamento a violência, e como consequência, em 2006 foi instituída a Norma Técnica de Uniformização dos Centros de Referência de Atendimento à Mulher em Situação de Violência. Os Centros são estruturas essenciais do programa de prevenção e enfrentamento à violência contra a mulher. De acordo com a Norma Técnica de Uniformização (2006, p.16) o objetivo primário da intervenção é cessar a situação de violência vivenciada pela mulher, promovendo meios para que ela fortaleça sua autoestima e tome decisões relativas à situação de violência por ela vivenciada. Promovendo com isso, a interrupção do ciclo de violência e a prevenção de futuros atos.

O Centro de Referência da Mulher Maria Bonita (CRMMB) do município de Caruaru é interligado ao Eixo de 
Enfrentamento à Violência da Secretaria de Políticas para Mulheres, e traz atividades para estimular o empoderamento das mulheres atendidas pelo serviço, dentre elas, existe o Grupo Reflexivo "As Marias". O grupo é um trabalho de cunho educativo que visa problematizar a violência, desconstruindo as práticas discursivas que retroalimentam e legitimam a violência de gênero.

A temática trazida pelo Grupo Reflexivo As Marias é pertinente ao Movimento Feminista, que para Ivone Gebara (2017, p.10) é um movimento de emancipação, ruptura e novas construções de sentido, visando a quebra das formas tradicionais masculinas de se pensar o mundo. A partir das epistemologias feministas pode-se verificar novas possibilidades de conhecimento em que a mulher não é subalternizada ou mantida na perpetuação do patriarcado.

Através das atividades realizadas no Grupo Reflexivo as Marias, pode-se verificar a ressignificação das violências sofridas, no sentido que as mulheres têm a possibilidade de se reconhecerem na dor das outras. Muitas vezes as mulheres vítimas de violência não se reconhecem em posição de subalternidade, e por outras vezes acreditam que são as únicas que passam por essas situações. O grupo auxilia na identificação da violência através do olhar do outro e para o outro, construindo saberes outros sobre a melhor forma de combater as sequelas das violências sofridas.

Nesse sentido, Nunes (2001, p.307) traz o posicionamento que ignorar estes temas implica silenciar aspectos determinantes do conhecimento da sociedade e da cultura, das formas de poder, das formas de exclusão e de opressão que não podem ser ditas pelo conhecimento fundado na teoria convencional.

Assim sendo, é de extrema importância validar outros saberes como construção para o fim da violência contra mulher, trazendo epistemologias diversas. A partir dessas perspectivas, o objetivo geral é refletir sobre como o Grupo Reflexivo

As Marias contribui para o empoderamento das mulheres através do reconhecimento no outro, compreendendo novas formas de construção de conhecimento, e como objetivos específicos, busca-se demonstrar como a ótica das epistemologias do sul corrobora com as ações do Grupo, assim como, visibilizar como ocorre essa ressignificação das violências sofridas entre as mulheres participantes do Grupo.

\section{Discussão teórica}


O Grupo Reflexivo As Marias teve início no ano de 2014, onde tinha por objetivo levar às mulheres informações sobre violências, seus direitos e conversar sobre os danos psicológicos. Somente em 2017 o Grupo passou a ter o objetivo do cuidado de si, com trabalho educativo que visa problematizar a violência, desconstruindo as práticas discursivas que legitimam a violência de gênero e colocam a mulher em condição de subalterna, invisibilizada e negligenciada.

O trabalho com as mulheres vítimas de violência é realizado de forma sutil, utilizando como base as perspectivas feministas como forma de ressignificar essa violência, que por muitas vezes acaba sendo tratada de forma errônea, deixando de lado o empoderamento da mulher como um dos principais meios de combate contra a violência. Castañeda traz, em seus estudos sobre o feminismo que:

El centro de su reflexión es la explicación de la multiplicidade de factores que se concatenan para sostener la desigualdad entre mujeres y hombres baseada em el gênero, la cual está presente todos os âmbitos de la sociedade marcada por la dominación patriarcal. (2008, p. 12).

A partir dessa perspectiva, o grau de autonomia organizativa e intelectual das mulheres articuladas aos espaços públicos é imensa, e traz os reconhecimentos culturais nas vidas das mesmas. Contudo, a sociedade ainda está enraizada na ideia de subalternação da mulher, e isso traz a necessidade do feminismo nos espaços de políticas públicas. Na concepção de Catarina Martins (2016, p. 267), o feminismo implica uma reflexão abrangente que entenda o cárcere sistemático da opressão feminina, bem como um pensamento combativo e empenhado em acabar com essa opressão.

É nesse sentido que Martins (2016, p. 271) afirma que "mais do que formular a noção de cultura, que sempre serviu como arma de combate anticolonial, cristalizando-se em narrativas de cunho patriarcal" faz-se necessário ressignificar a compreensão de cultura através da violência, em si e na outra.

A partir disso, percebe-se a importância da metodologia feminista na construção de conhecimentos outros, e nesse caso, na aplicação no projeto do Grupo Reflexivo As Marias. Corroborando com esse entendimento, a autora Castañeda (2008, p.19) aduz que "la investigación sobre la metodología feminista es que se puede caracterizar, pero no necesariamente definir. Es como un campo de transformación, flexible, dinámico y libre".

Nessa perspectiva, como o feminismo tem espaço para transformação e liberdade de conhecimentos, permite que a construção desses ultrapasse a 
ciência científica e adentre na ciência social, construída através das vivências partilhadas de mulheres vítimas de violência.

A ideia é sair dessa hierarquização do saber e organizar novas formas de diálogos e ação. Para Nunes (2010, p. 280) nenhum saber poderá, assim, ser elevado à condição de padrão a partir do qual será aferida a validade dos outros saberes sem considerar as condições situadas da sua produção e mobilização e as suas consequências.

Com isso, pode-se perceber a oposição a soberania epistêmica, onde subalternizar outros conhecimentos. Nunes (2010, p. 263) traz a reflexão que a caracterização dos diferentes saberes e modos de conhecer a definição das condições da sua validação passam, nessa concepção, por um caminho que recusa a ambição legislativa da epistemologia e a possibilidade de qualquer forma de soberania epistêmica.

O Grupo Reflexivo As Marias permite a construção social dos saberes, a partir da fala de cada integrante do grupo, compartilhando suas vivências e olhares sobre o mundo. A epistemologia, que para Santos (2010, p.09) "é toda a noção ou ideia, refletida ou não, sobre as condições do que conta como conhecimento válido", precisa abranger todos os saberes, deixando de abranger exclusivamente os conhecimentos científicos, dando igual dignidade e valor a todos os saberes, à saberes outros, contextos outros.

Esses saberes são construídos a partir da "fluidificação das fronteiras entre as ciências naturais, as ciências sociais e as humanidades, dando origem a novas configurações de saberes e de racionalidades que, sendo articuladas localmente, têm implicações no modo como são concebidas as relações entre o local e o global" (João Nunes, 2001, p. 305).

As buscas de alternativas à dominação e a opressão dentro da subordinação são características das epistemologias do sul, que é utilizada na organização de conhecimentos durante as reuniões do Grupo Reflexivo As Marias. As condições de produção, mobilização e consequências devem ser consideradas na validação de novos conhecimentos.

Segundo os estudos de Boaventura Santos (2010, p.09) toda experiência social produz e reproduz conhecimento, e ao fazê-lo, pressupõe uma ou várias epistemologias. No caso do Grupo Reflexivo a epistemologia que se faz presente nas reuniões é a do Sul, que para Santos:

Designamos a diversidade epistemológica do mundo por epistemologias do Sul. O sul é aqui concebido metaforicamente como um campo de desafios epistêmicos, que procuram separar os danos e impactos historicamente causados pelo capitalismo e sua relação colonial com o mundo. (2010, p.12). 
A busca por minimizar (ou extinguir) essa subalternização dos conhecimentos, é apontada por Santos (1995, p.505-507) no sentido que o sul não é apenas um espaço geográfico e histórico, mas também uma metáfora, que expressa as diferentes subalternidades e resistências à globalização hegemônica.

Com isso, pode-se perceber que o Grupo Reflexivo As Marias é resistência a subalternidade das mulheres vítimas de violência. Uma vez que, o grupo permite novas construções de conhecimento sobre a violência e novas perspectivas de empoderamento, a partir do olhar do outro sobre o outro, e do olhar do outro sobre si.

\section{Metodologia}

Heleieth Saffioti (2015, p.11), afirma que sempre que se faz uma pesquisa com a finalidade de se verificar quais são as maiores preocupações dos brasileiros, aparecem, infalivelmente, o desemprego e a violência. É justamente sobre a violência de gênero e as suas formas de ressignificação, assim como a construção de conhecimentos pautados a partir da violência que foram estudados.

A pesquisa realizada foi qualitativa, que é de caráter relacional, já que envolve participação, cooperação, interação. Sob essa perspectiva, Chizotti (1998, p.79) analisa como pressuposto da pesquisa qualitativa a existência de "uma relação dinâmica entre o mundo real e o sujeito, uma interdependência viva entre o sujeito e o objeto, um vínculo indissociável entre o mundo objetivo e a subjetividade do sujeito".

A partir disso, a pesquisa qualitativa proporciona uma redefinição da pesquisa social e contribui para superação do dualismo realidade/interpretação. Alcançando assim, a centralidade na linguagem, e que se encontra relacionada a culturas, tempos e contextos específicos que garantem alguma estabilidade dos sentidos sociais e da própria investigação científica.

Em relação ao trabalho, foram realizados acompanhamentos nas atividades do Grupo Reflexivo As Marias no ano de 2018, sendo todos de caráter sistemático e permanente as vivências das mulheres que participaram dos encontros.

Para entender sobre as contribuições éticas e políticas em torno da ressignificação da violência é necessário existir interações com as outras mulheres que também foram/são vítimas de violência. Pode-se notar que a psicologia transpessoal, com a disponibilidade de escutar, de falar, de sentir, se posicionar e responsabilizar-se, oportuniza possibilidades de transformação. 
O método permitiu que após a consideração de fatos particulares possase chegar a uma percepção generalizada de um determinado grupo. A pesquisa foi realizada através de fontes bibliográficas de autores que discutem a temática de gênero, epistemologias do sul e feminismo. Assim como, através da vivência das atividades do Grupo Reflexivo as Marias e para que chegasse a conclusão de como as mulheres conseguiram ressignificar suas histórias através de conhecimentos partilhados.

\section{Resultados}

Para uma melhor apresentação dos resultados da pesquisa, faz-se necessário compreender a dinâmica do Grupo Reflexivo As Marias. Primeiramente, antes do contato com o grupo, as mulheres são atendidas e acolhidas pelo Centro de Referência da Mulher Maria Bonita

No primeiro momento, ocorre o atendimento realizado na recepção do Centro, onde as mulheres são acolhidas e suas dúvidas sobre os serviços são sanadas. O segundo momento corresponde ao atendimento técnico com assistente social, psicóloga e advogada, onde a equipe multidisciplinar traça os caminhos que a mulher pode percorrer para corroborar com o fim da violência e suas consequências. É interessante que identificada a violência, a vítima seja acompanhada à Delegacia da Mulher (DEAM), onde será registrado o Boletim de Ocorrência, e se for o caso, solicitados os exames sexológicos e traumatológicos. É de bom alvitre mencionar que a equipe do CRMMB só acompanha a vítima à delegacia se for da vontade da mulher, respeitando sempre a autonomia da atendida.

Se a equipe multidisciplinar verificar que é caso de ameaça de morte, será solicitado o Serviço de Abrigamento previsto pela Lei Estadual de Pernambuco no 13.977/2009, onde a Secretaria de Políticas para Mulheres do Estado oferece casas abrigo, nas quais as mulheres recebem assistência do Estado para sair do ciclo de violência. As casas ficam em localizações desconhecidas para dificultar o acesso às vítimas, e estas podem ser acolhidas de 1 dia a 3 meses, somente sendo desabrigadas se a violência cessar ou se for de vontade da vítima.

O serviço é oferecido com o intuito de identificar quais são as violências sofridas pela mulher atendida e com isso, procurar formas de romper com o ciclo de violência e minimizar as consequências. A assistente social verifica se existem benefícios assistenciais disponíveis para a atendida, realiza encaminhamentos às redes de proteção, enquanto a advogada analisa 0 inquérito policial, encaminhamentos a outras assessorias jurídicas e 
acompanhamentos em audiências. Já a psicóloga atua no reconhecimento da mulher como vítima de violência, e seu posterior empoderamento.

O que pode-se perceber quando a mulher chega ao serviço é que ela apresenta desconfiança em relação a rede de enfrentamento, já que por muitas vezes ela foi à delegacia e não recebeu o tratamento adequado, registrou mais de um Boletim de Ocorrência e não observou sua situação melhorar, e também já ligou para a polícia e esta ou não compareceu ou chegou tarde demais. Sobretudo, a mulher apresenta-se no seu profundo sentimento de desamparo e isso limita a possibilidade de enxergar-se para além das vulnerabilidades sociopolíticas, só se reconhece na condição de vítima da violência.

É justamente esse conjunto de situações que deixa a mulher fragilizada, aumentando a vulnerabilidade e a subalternidade. Com a finalidade de levar possibilidades de um novo olhar e o reconhecimento diante de tantas violências sofridas, o Grupo Reflexivo As Marias traz suas atividades.

O Grupo apresenta elementos da construção humana significativa, no momento em que as atendidas refletem sobre as violências e não se reconhecem mais como culpadas, visto que a mulher ao lado também passou por situações semelhantes. É como se reconstruir na dor e na força da outra. Os processos de articulação dentro do discurso são de extrema importância, para Sales (2014), operam num campo cruzado por projetos articulatórios antagonistas, práticas hegemônicas nas quais se dá a articulação/desarticulação das práticas e papéis sociais, conforme a constituição das diversas identidades sociais, que estão sujeitas àquelas práticas articulatórias, não sendo intrínseca ou integralmente adquiridas, mas definitivamente constituídas.

Além disso, o Grupo Reflexivo proporciona que as mulheres tirem dúvidas com a equipe disciplinar de maneira mais intimista e confortável, fortalecendo os vínculos entre quem oferece o serviço e quem aceita.

Ao observar o que foi refletido e problematizado no grupo, é possível ver o reflexo na vida das mulheres. Existem mulheres que são atendidas pelo Centro e que optam por não participarem do Grupo Reflexivo, contudo, as mulheres que participam têm se empoderado com mais rapidez do que as que não interagiram. Reflexo das atividades no Grupo.

A ressignificação ocorre quando uma mulher chega ao serviço desacreditada em si mesmo, achando que é culpada pela violência sofrida e envergonhada por estar ali, e depois de receber acolhimento, atendimento e participar das atividades do Grupo acaba por se reconhecer além de vítima, mas como uma mulher forte, assim como todas as outras.

O conhecimento construído no grupo assemelha-se à ideia trazida por Martins (2016, p. 267), onde implica uma reflexão abrangente que entenda o 
cárcere sistemático da opressão feminina, bem como um pensamento combativo e empenhado em acabar com essa opressão.

Com isso, Gebara (2017, p. 46) aduz que "quando nós feministas denunciamos a força da opressão das sociedades falocêntricas, estamos querendo denunciar a simbologia cultural e social que se expressa através do falo, ou seja, do lugar simbólico da dominação masculina".

Em relação aos encontros do Grupo, faz-se necessário compreender o relato de experiência de Karinny Oliveira:

Ao longo dos encontros, à medida que o processo de individualização se consolidava, as usuárias experimentaram a construção de uma consciência crítica de si mesmas e, consequentemente, a re-significação de suas identidades. Foram utilizadas dinâmicas para favorecer mecanismos projetivos e de identificação entre as usuárias, de forma que a história narrativa de cada uma fosse capaz de espelhar a das demais, valorizando os aspectos de resistência e resiliência presente em cada narrativa. Desta forma, as características valorizadas pelo coletivo e presente em cada subjetividade foram compartilhadas pelo grupo, fazendo surgir um empoderamento coletivo a partir de cada forma de resistência apresentada coletivamente. (2018, p. 13-14.).

Por conseguinte, é notório por todas que participam do Grupo a diferença de sua percepção em relação ao que é violência e como romper o ciclo. As Marias permitem o partilhar de conhecimentos e culturas, e com isso, a construção de um conhecimento outro sobre o combate da violência e o empoderamento.

Ademais, o conhecimento científico de estudiosos e escritores sobre o tema violência é de grande relevância para reflexão e compreensão sobre o tema, contudo, é imprescindível validar os conhecimentos construídos pelas próprias mulheres vítimas de violência. Afinal, as dores são sentidas por elas, então nada mais justo que elas tenham voz, tenham poder de fala e o direito a escuta.

\section{Considerações finais}

É importante destacar que o combate à violência de gênero vai além de legislações específicas e projetos de conscientização contra violência, mas adentra em políticas públicas com a finalidade de construir novos saberes a partir da vivência das mulheres vítimas. Através dessa pesquisa, pode-se perceber o quanto é importante o reconhecimento de

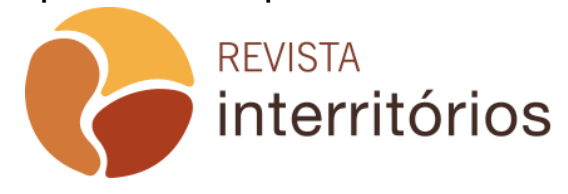


conhecimentos outros, pautados em realidades diversas. A ressignificação da violência ocorre com o olhar do próximo a si mesmo. Com menos atendimento técnico e mais atendimento humanizado.

O Grupo Reflexivo As Marias é uma proposta para auxiliar as mulheres no sentido da ressignificação da violência, a saírem do lugar de subalternização que a sociedade as coloca sem nenhum consentimento e irem à busca de novas fortalezas. A construção social do conhecimento sobre o empoderamento da mulher e a ruptura do ciclo de violência mostrou-se extremamente eficaz nas atividades do Grupo.

No que tange a metodologia do grupo, são utilizadas as epistemologias do sul como forma de construção de conhecimentos e a epistemologia feminista como meio de ressignificação das violências. A partir do contato das mulheres com novas vivências, novas realidades, e novos olhares acabam por ressignificarem suas próprias vidas.

Por conseguinte, percebe-se que as vulnerabilidades das vítimas são enormes, e diante disso, não se tem como fazer o uso de um método universal e construído através de outras culturas para todos os grupos de mulheres. As atividades no Grupo permitem que as atendidas sejam protagonistas de suas próprias histórias e conhecimentos, e a partir dessas novas epistemologias é que a política pública deve agir.

A conclusão que se tem é que para ter um atendimento eficaz é preciso construir juntas esse conhecimento, tirar o sentimento de solidão e trazer 0 coletivo para romper com todas as barreiras do patriarcado. O Grupo Reflexivo As Marias atua nessa construção de conhecimentos para o empoderamento coletivo e individual.

\section{REFERÊNCIAS}

BRASIL. Lei no 13.104/06. Publicada no DOU dia 07 de agosto de 2006.

CASTAÑEDA, M.P.S. Metodologia de la investigacíon feminista. Imprenta Evolution. Guatemala, 2008.

CHIZZOTTI, A. Pesquisas em Ciências Humanas e Sociais. São Paulo: Cortez, 1998.

ESTEBAN, M. P. S. Pesquisa Qualitativa em Educação: fundamentos e tradições. Porto Alegre: AMGH, 1998, p. 78-80.

GEBARA, Ivone. Filosofia Feminista: uma brevíssima introdução. São Paulo: Edições Terceira Via, 2017.

MARTINS, Catarina. Nós e as Mulheres dos Outros. Feminismos entre o Norte e a África. In RIBEIRO, M.G.; RIBEIRO, A.S. (Org). Geometrias da memória: 
configurações pós-coloniais. Edições Afrontamento. 2016.

NUNES, J. A. O resgate da Epistemologia. In SANTOS, B. S.; MENESES, M. P. (Org.).Epistemologias do Sul. Porto São Paulo: Cortez, 2010.

NUNES, J. A. Teoria crítica, cultura e ciência: O(s) espaço(s) e o (s) conhecimento(s) da globalização. In SANTOS, B. S.(Org.). Globalização: fatalidade ou Utopia?.

Porto. Rainho \& Neves, Ltda./ Santa Maria da Feira, 2001.

SAFFIOTI, Heleieth I. B. Gênero, patriarcado, violência. $2^{\text {a }}$ ed. São Paulo:

Expressão Popular: Fundação Perseu Abramo, 2015.

SALES, R. Laclau e Foucault: desconstrução e genealogia. In: MENDONÇA, D.; RODRIGUES, L. P. (Orgs). Pós-Estruturalismo e Teoria do Discurso: em torno de Ernesto Laclau. Porto Alegre, 2014.

SANTOS, B.S; MENESES, M. P. (Org.). Epistemologias do Sul. Porto São Paulo: Cortez, 2010.

SANTOS, Boaventura de Souza. Toward a new common Sense. Law, Science and politics in the paradigmatic transition. Nova lorque: Routledge, 1995, 505-507.

OLIVEIRA, Karinny; CORDEIRO, Eugênia. A noção do cuidado de si: vivências compartilhadas entre mulheres em situação de violência doméstica e familiar. CONEDU. Editora Realize, Vol. 1, 2018. Disponível em: $<$ https://www.editorarealize.com.br/revistas/conedu/trabalhos/TRABALHO EV117 MD 1 SA18 ID9579 17092018210528.pdf>. 